\title{
In vitro Propagation and Ex vitro Rooting of Blueberry Plantlets
}

\section{Zhao Guang-jie, Wang Zhan-bin* and Wang Dan}

School of Forestry, Northeast Forestry University, Harbin, China, 150040

Key words: Blomidon, Tissue culture, In vitro regeneration, Rooting agent

\begin{abstract}
Effects of different concentrations of 2-ip and IBA in WPM basal medium for Blomidon blueberry in vitro propagation and four different rooting agents at the early stage after transplantation showed that $15 \mathrm{mg} / 1$ of 2-ip is the best concentration to induce shoots. For optimum in vitro root formation $10 \mu \mathrm{M}$ IBA was found to be best and four rooting agents for seedling transplantation according to their effects were No.2>, No.4>, No.3 >, water $>$ and No. 1.
\end{abstract}

\section{Introduction}

Blueberries (Vaccinium cyanococcus) are flowering plants produce one of the rare true blue fruits on earth. The species are native only to North America, but at Changbai Mountain area and Da Xinan Mountain area in China, the natural conditions are suitable for growing of blueberries, especially the lowbush blueberry (Vaccinium angustifolium Ait.) cultivar "Blomidon" (Drucie and Percival 2003). This cultivar is winter hardy, and hence the first suitable species in Alpine areas (Yadong et al. 1994). Traits such as low maintenance, low agrochemical input requirements, resistance to pests, ease of mechanical harvest (Drucie and Percival 2003), the high anthocyanin content of lowbush blueberry (Kalt et al. 1999) contribute to its important therapeutic values including antitumor (Kamei et al. 1995), antiulcer (Cristoni and Magistretti 1987), antioxidant and anti- inflammatory activities (Wang et al. 1999). Due to these attributes there has been renewed interest and efforts in breeding lowbush blueberry.

Traditionally, softwood, semi-hardwood, and hardwood cuttings have been used to propagate blueberries (Samir 2007). This kind of propagation is slow and is difficult for rooting. The most effective propagation system for new cultivars of blueberries is micropropagation because it produces plenty of plants rapidly, and hence micropropagation of blueberries has been developed over the last 30 years (Fukui et al. 1991, Gonzalez et al. 2000, Isutsa et al. 1994). But plants derived from tissue culture of blueberries grow less vigorously and the rooting

*Corresponding author, <wangzbchina@yahoo.com.cn>. 
percen-tage is very low. The aim of the present research was to optimize the cultural conditions of Blomidon blueberry explants, and to determine the influence of IBA and 2-ip concentration on the proliferation rate and rooting percentage of explants.

\section{Materials and Methods}

Lowbush blueberry plants from a greenhouse of Agriculture Institute of Daxinganling were used as a starting material. 2-ip and IBA were both purchased from Promega.

(i) Rooting agent No. 1: "Chun Lu" (Hei Longjiang Suinong Pesticide Co. Ltd.) the main component is NAA.

(ii) Rooting agent No. 2: "Sheng Genkuai" (Suihua Fertilizer Co. Ltd.), comprises yellow humic acid as the effective ingredient.

(iii) Rooting agent No. 3: "Bao Tiangen" (Suihua Fertilizer Co. Ltd.), IAA is the essential component.

(iv) Rooting agent No. 4: "Shenggen Zhuangmiao Ji" (Shandong Changle Baofeng Fertilizer Co. Ltd.), is composed of BAU-3, diethyl aminoethyl hexanoate (DA-6), the soluble chitin, amino acids etc.

Young, actively growing Blomidon stems of cultivars were harvested from plants being maintained in a greenhouse. Stem segments, $3 \pm 5 \mathrm{~cm}$ long, were surface disinfected; they were rinsed in running water and washed in a solution of $2 \%(\mathrm{v} / \mathrm{v})$ mild liquid detergent for $2 \mathrm{~min}$, the shoots were surface sterilized in a solution of $0.1 \%$ Tween 20 (polyoxyethylene sorbitan monolaurate) for two eight min, and then rinsed three times in sterilized deionized water, then the sections were cut into $1-2 \mathrm{~cm}$ single node with leaves intact pieces for next step.

WPM (Woody Plant Medium) was used as a basal medium for blueberry micropropagation (Gonzalez et al. 2000, Isutsa et al. 1994). It was used for micropropagation of lowbush blueberry supplemented with sucrose (25 g/l), agar $(6 \mathrm{~g} / \mathrm{l})$, and with different concentrations of IBA and 2-ip. The $\mathrm{pH}$ was adjusted to 5.2 before autoclaving at $121^{\circ} \mathrm{C}$ for $20 \mathrm{~min}$. Unless noted otherwise, cultures for all experiments six explants were grown per $450 \mathrm{ml}$ culture bottle, which contained $80 \mathrm{ml}$ of the culture medium.

The purpose of this experiment was to determine the effect of 2-ip concentration on shoot induction and proliferation in lowbush blueberry cultivars. The WPM medium was supplemented with different concentrations of 2-ip $(0.25,2.5,5.0,10,15,20$ and $25 \mathrm{mg} / \mathrm{l})$ on the 'Blomidon' cultivars over the initial cultural and one subculture period. There were ten culture bottles prepared for each cultivar treatment. Single node explants $(1-2 \mathrm{~cm})$ with leaves intact used for the initial culture. Subculturing was done with the nodal explants 
(with one node, leaves intact) of randomly selected shoots in each bottle from the initial culture. The experiment was repeated thrice.

Elongated shoots ( $1-2 \mathrm{~cm}$ long) were excised individually and cultured on the WPM containing different concentrations of IBA $(0,2.5,5,10,15,20 \mu \mathrm{M})$ to obtain optimum rooting. For subculturing $1-2 \mathrm{~cm}$ long nodal explants (with one node, leaves intact) were used with the nodal explants of randomly selected shoots in each bottle from the initial culture. The experiment was repeated thrice.

Culture bottles placed upright and maintained at $24-28^{\circ} \mathrm{C}$ under a $16 \mathrm{hrs}$ photoperiod at illumination intensity of 2000 lux.

The primary explants were cultured for four weeks; then randomly chosen axillary shoots were excised and cultured on the same medium for another four weeks for the second culture period (i.e., the first subculture). After four weeks of culture, in each period, growth characteristics such as number of shoots $(1.0 \mathrm{~cm}$ long) per responding explants, mean shoot length (for responsive explants), mean number of leaves per shoot, and mean shoot vigor (for all of the surviving explants) of surviving explants were measured for each treatment. The vigor was determined on the basis of visual assessment, on a scale of one (strongly vitrified, necrotic and/or malformed shoots) to eight (fully normal and healthy shoots).

When seedling height and root length were over 5 and $1 \mathrm{~cm}$, respectively plugs of the culture bottles were kept open and after three days rooted seedlings were taken out from the culture tubes. The roots were washed to free the culture medium. Then the seedlings were transplanted in pots with black soil and sand $(1: 1)$. After transplantation the seedlings were watered and then covered with plastic film. The pots with the transplanted seedlings were kept at $22 \pm 2{ }^{\circ} \mathrm{C}, 95 \%$ humidity at $16 \mathrm{hrs}$ photoperiod with 2000 lux for growing.

Five plots of $80 \mathrm{~cm} \times 80 \mathrm{~cm}$ were set, corresponding to rooting agents $1,2,3$, 4 and clear water. Sixty seedlings were transplanted in each plot with $8 \mathrm{~cm} \times 8$ cm spacing, according to instruction lowest concentration: root agent No. 1 was diluted with water in the ratio of $1: 106$, root agent No. 2 at $10-8 \mathrm{M}$, root agent No. 3 at $10-4 \mathrm{M}$, and root agent No. 4 at $10-7 \mathrm{M}$ concentrations, sprayed the corresponding plots every after seven days and the experiment was repeated two times.

The first observations was made after ten days from the beginning of the experiment. Subsequent observations were made once a week for a period of six weeks. For every observation, 16 shoots were collected from each experiment and the number of root tips/shoot was counted. In addition, the maximum length of the roots and the mean length of the root branches/plant were measured. Statistical analyses were made from the data collected at the last observation time. 


\section{Results and Discussion}

At about $70-80 \%$ explants were established axenically according to the disinfection method described elsewhere. A few explants $(10-20 \%)$ were contaminated because of endophytic parasite. Elongated shoots are produced from the explants on WPM containing 2-ip, buds appeared to be proliferated directly from the node via the axillary branching of shoots from the original explants, and they showed slight browning after six weeks (Fig. 1), $5-6 \mathrm{~cm}$ long, three - five shoots per explants were produced.

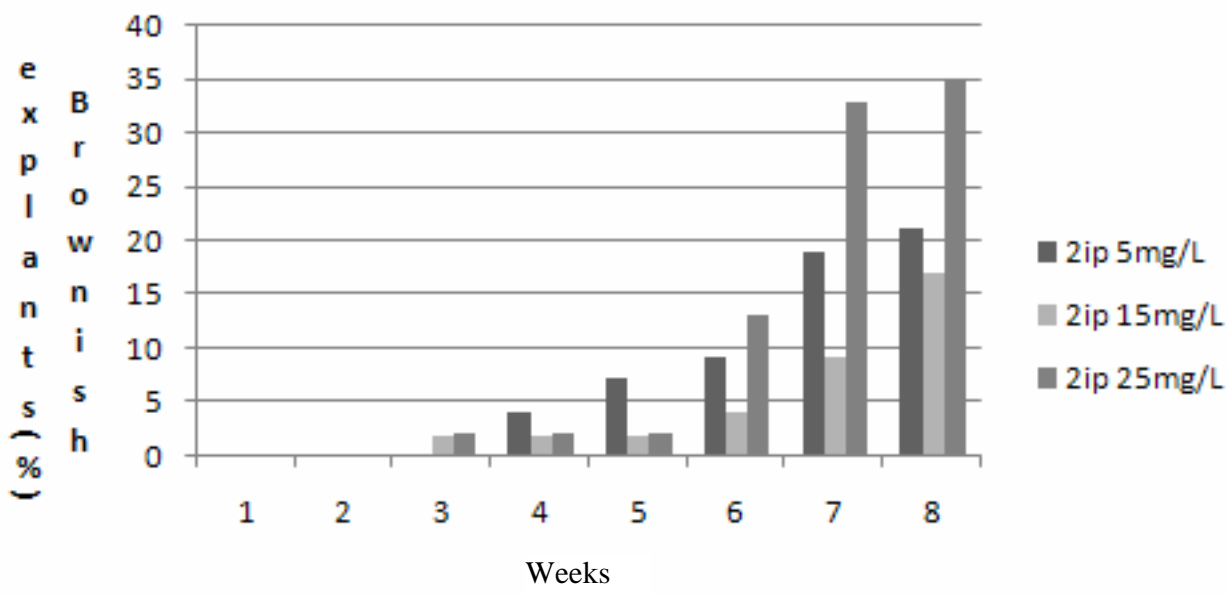

Fig. 1. Effects of 2-ip concentration on browning of the Blomidon. Percentage of brownish Blomidon explants during eight weeks in culture.

Explants formed shoots on the WPM medium with or without 2-iP. Shoots proliferated directly from the nodes of the original explants and in subsequent subculture period, shoots proliferated both from axillary buds and callus. No hyperhydric shoots were observed. The Table 1 showed that 2-ip concentrations and culture period (initial culture vs. subculture) significantly affected shoot induction; shoots formed more often at higher 2-ip concentrations in the subculture period.

Callus formed occasionally at the base of the explants grown with $0-5 \mathrm{mg} / 1$ 2-ip with the smallest leaves and partly browning, the seedling was quite short and slender, but shoots proliferated directly from the node, via axillary branching of buds from the original explants. Calluses formed more at higher 2ip concentrations $(10-20 \mathrm{mg} / \mathrm{l})$ in the culture medium, the leaves were more fresh-green and thicker. Increasing the concentration of 2 -ip to $25 \mathrm{mg} / 1$ could form more callus and branches in the most of the in vitro stem segments, but the callus turned brown seriously and completely inhibited the growth (Fig. 2A).

Analysis showed that 2-ip concentration significantly affected shoot regeneration, the number of shoots per explants increased while shoot height, 
leaf number per shoot and shoot vigor decreased with increasing concentrations (Table 1). The effects of subculturing on the shoot size were as follows: shoots increased from 1.5 to 3.6, when 2-ip concentration was increased from 0 to 15 $\mathrm{mg} / \mathrm{l}$, shoot length increased from 2.0 to $5.5 \mathrm{~cm}$, and the number of leaves increased from 5.1 to 11.1 per explants, but when 2-ip concentration was increased more than $20 \mathrm{mg} / \mathrm{l}$, shoot length and the number of leaves decreased.

Table 1. Effect of 2-ip conc. on shoot induction and proliferation from Blomidon (60 explants per 2-ip concentration and per culture period).

\begin{tabular}{|c|c|c|c|c|c|c|c|}
\hline \multirow{2}{*}{$\begin{array}{l}\text { 2-ip conc. } \\
(\mathrm{mg} / \mathrm{l})\end{array}$} & \multicolumn{2}{|c|}{$\begin{array}{l}\text { Shoots per explant } \\
\text { (No.) }\end{array}$} & \multicolumn{2}{|c|}{ Shoot length $(\mathrm{cm})$} & \multicolumn{2}{|c|}{$\begin{array}{c}\text { Leaves per explant } \\
\text { (No.) }\end{array}$} & \multirow{2}{*}{$\begin{array}{c}\text { Vigor } \\
\text { (scale } \\
1-8)\end{array}$} \\
\hline & $\begin{array}{c}\text { Intial } \\
\text { culture }\end{array}$ & Subculture & $\begin{array}{c}\text { Intial } \\
\text { culture }\end{array}$ & $\begin{array}{c}\text { Subcultur } \\
\mathrm{e}\end{array}$ & $\begin{array}{c}\text { Intial } \\
\text { culture }\end{array}$ & Subculture & \\
\hline 0 & 1.0 & 1.5 & 1.4 & 2.0 & 4.3 & 5.1 & 4.4 \\
\hline 2.5 & 1.1 & 1.7 & 1.7 & 2.2 & 5.7 & 6.6 & 5.2 \\
\hline 5 & 1.5 & 1.9 & 2.1 & 3.6 & 6.9 & 7.2 & 6.0 \\
\hline 10 & 1.7 & 2.5 & 2.6 & 4.7 & 7.2 & 9.5 & 7.0 \\
\hline 15 & 2.3 & 2.8 & 3.6 & 5.5 & 9.5 & 11.1 & 7.5 \\
\hline 20 & 2.6 & 3.0 & 2.8 & 3.1 & 8.7 & 7.7 & 6.5 \\
\hline 25 & 2.8 & 3.3 & 1.4 & 1.7 & 5.5 & 6.8 & 5.4 \\
\hline 30 & 3.0 & 3.6 & 1.2 & 1.3 & 4.2 & 4.7 & 4.6 \\
\hline
\end{tabular}

Multiple shoots were separated and 1 - $2 \mathrm{~cm}$ long shoots were excised during subculture and used for rooting in different concentrations of IBA. This was done to find the optimal conditions of IBA concentration for in vitro rooting. Rooting efficiency was satisfactory by increasing the concentration of IBA from 5 to 10 $\mu \mathrm{M}$ (Table 2), main root was robust and branch root was well developed. Robust and highest number of roots (9.0 per shoot) were formed in WPM supplemented with $10 \mu \mathrm{M}$ IBA; when IBA concentration was higher than $15 \mu \mathrm{M}$, main root was too thick and the branch roots became slender (Fig. 2B).

Table 2. Effects of IBA with different concentration on rooting.

\begin{tabular}{ccccc}
\hline $\begin{array}{c}\text { IBA conc. } \\
(\mu \mathrm{M})\end{array}$ & $\begin{array}{c}\text { Rooting rate } \\
(\%)\end{array}$ & $\begin{array}{c}\text { Root length } \\
(\mathrm{cm})\end{array}$ & $\begin{array}{c}\text { Root number } \\
(\text { No./plant })\end{array}$ & $\begin{array}{c}\text { Plant vigor } \\
(\text { scale: } 1-8)\end{array}$ \\
\hline 0 & 53.3 & 0.8 & 3.9 & 5 \\
2.5 & 79.2 & 1.4 & 6.5 & 5.5 \\
5 & 75.8 & 2.3 & 7.6 & 6.6 \\
10 & 93.1 & 3.9 & 9.0 & 7 \\
15 & 84.6 & 1.6 & 7.8 & 6.5 \\
20 & 90 & 1.0 & 9.3 & 6 \\
\hline
\end{tabular}

After micropropagation, plants were transfered to soil for acclimatization under glasshouse conditions, $80 \%$ of the plantlets survived and showed healthy 
and active growth when cultured on a fertilization system and under the environmental conditions established. Brownish plantlets appeared in each treatment, when transplanted at 15 days (Fig. 2B); after 29 days some of the transplanted plants began to die. The leaves of the survived transplanted seedlings were fresh-green and completely extended, the root started to elongate.
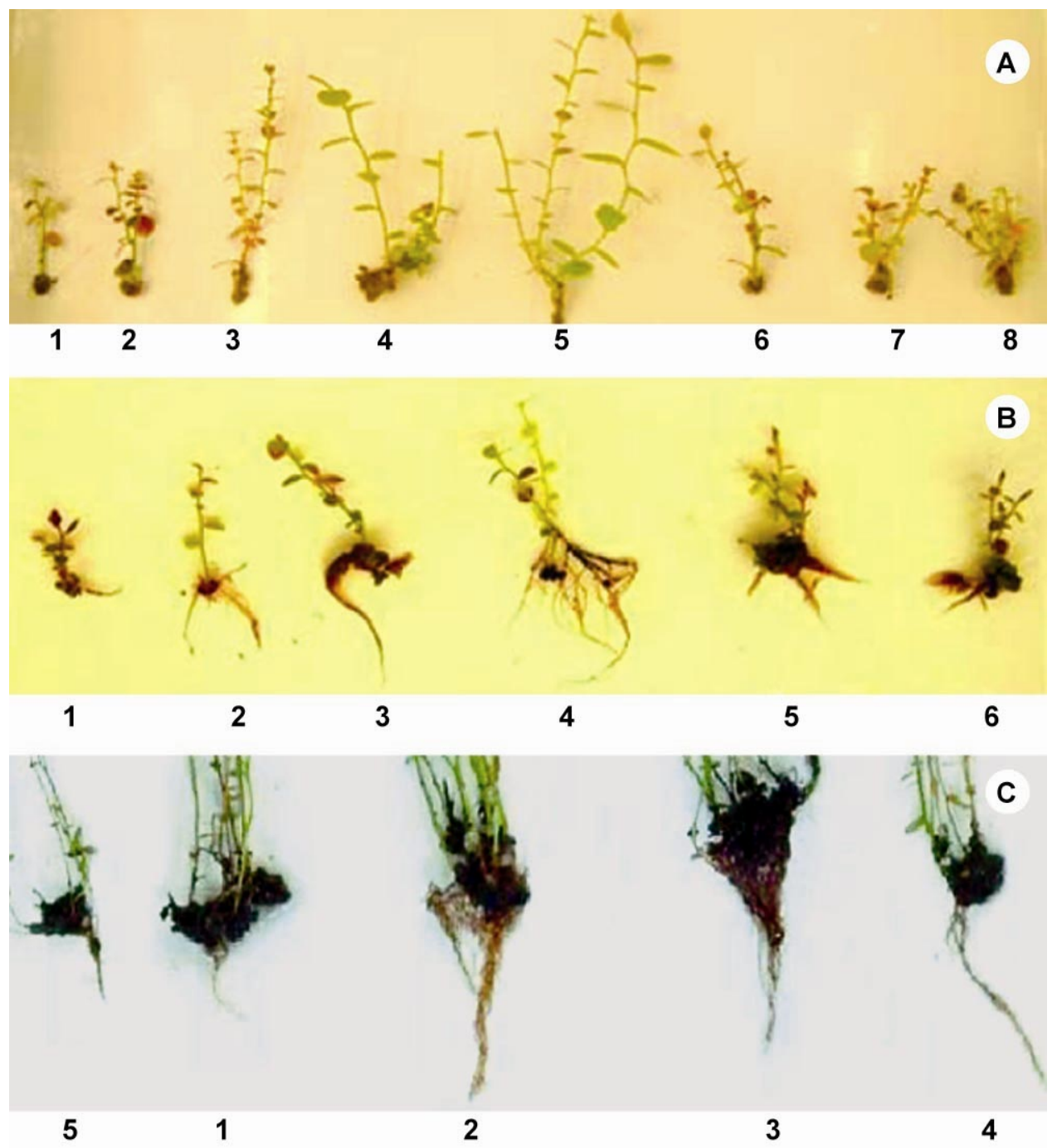

Fig. 2: A. Effects of 2-ip with different concentrations on bud induction and proliferation in the subculture period. In vitro shoots (1-8) developed from nodal segments after four weeks on $0,0.25$, 2.5, 5.0, 10,15, 20 and $25 \mathrm{mg} / 1$ 2-ip. B. Effects of IBA with different concentrations on rooting of Blomidon from tissue culture derived seedlings. In vitro roots (1-6) developed from nodal segments after four weeks on $0,2.5,5,10,15,20 \mu \mathrm{M}$ IBA. C. Effects of four rooting agents on the seedlings transplanted of Blomidon plantlets 1 - 5, respectively for rooting agent No. 1, rooting agent No. 2, rooting agent No. 3, rooting agent 4 and clear water treatment after 36 days. 
The exogenous application of four rooting agents through direct spraying on plantlets significant elongation of main root in three rooting agents as compared to the control (rooting agent No. 4) produced the higher length $(1.94 \mathrm{~cm})$ as compared with the rest of the treatments, but roots were slender and most of the individuals died in all treatments at the later stage of growth. After 36 days, total root length recorded for the control treatment was $1.36 \mathrm{~cm}$ while the rooting agent No.1 produced the lower root length $(1.17 \mathrm{~cm})$. Plantlets treated with rooting agent No. 2 and rooting agent No. 3 showed similar intermediate root length (1.55 and $1.61 \mathrm{~cm}$, respectively, Table 3), the root system of plantlets treated with rooting agent No. 2 was uniformly distributed (Fig. 2C) and the death rate was the lowest (Table 3).

Table 3. Effects of four rooting agents on death rate and average root length of transplanted seedlings.

\begin{tabular}{lcc}
\hline Treatment & $\begin{array}{c}\text { No. of plants died } \\
(\text { No. })\end{array}$ & $\begin{array}{c}\text { Average root length } \\
(\mathrm{cm})\end{array}$ \\
\hline Rooting agent No. 1 & 15 & 1.17 \\
Rooting agent No. 2 & 5 & 1.55 \\
Rooting agent No. 3 & 10 & 1.61 \\
Rooting agent No. 4 & 7 & 1.94 \\
Control & 12 & 1.36 \\
\hline
\end{tabular}

Marcotrigiano and McGlew (1991) used ANOVA to determine as to whether concentration growth regulator affected the number of shoots produced in vitro from cranberry shoot-tip explants. They concluded that 2-ip for the production of number of shoots in cultivar as well as in the plants obtained from subculture. It was also reported that the 2-ip level greatly influenced the number of shoots per explants (Smagula and Harker 1997). In this experiment, $30.0 \mathrm{mg} / 1$ 2-ip produced the greatest number of shoots per explants, shoot vigor was the poorest in all concentrations (Table 1), this treatment produced small leaves, the shortest shoots, and more callus tissue than other concentrations. This result showed that higher levels of 2-ip inhibited the shoot induction and proliferation which was also suggested by Marcotrigiano and McGlew (1991). It is reported that high concentration of cytokinin can inhibit elongation of micropropagated shoots (Pereira 2006).

Subculture significantly increased shoot number, as against the number of shoots per explant in the initial culture (Table 1). Similar results were also reported by Marcotrigiano and McGlew (1991) for shoot-tip explants. However, shoot length, leaf number, and shoot vigor were similar in both culture periods. 
In vitro rooting had been described rarely in Vaccinium. Jaakola et al. (2002) reported rooting in lingonberry with IBA. There are some reports that blueberry was rooted in vitro with IBA treatment through dipping and transfer to hormone free medium afterwards (Eccher et al. 1986). In this study the authors examined the effect of IBA on root formation. Root initiation did not occur at the shoot base, but often originated from callus or leaves on the surface of the medium. Shoots cultivated on medium containing IBA remained green and most of them formed new leaves and shoots. IBA concentration was found to be significantly correlated with axial root length and shoot vigor (Fig. 2B). On average in all treatments, cuttings treated with 5-10 $\mu \mathrm{M}$ IBA produced longer roots and more number per stem than those produced by the control. 15 and $20 \mu \mathrm{M}$ IBA promoted the highest root number but lowest shoot vigor. $10 \mu \mathrm{M}$ IBA is the best concentration for rooting growth and rate (Table 2). Effects of IBA on Blomidon propagation have not been reported previously, Julia et al. (2007) found similar results in other blueberry species.

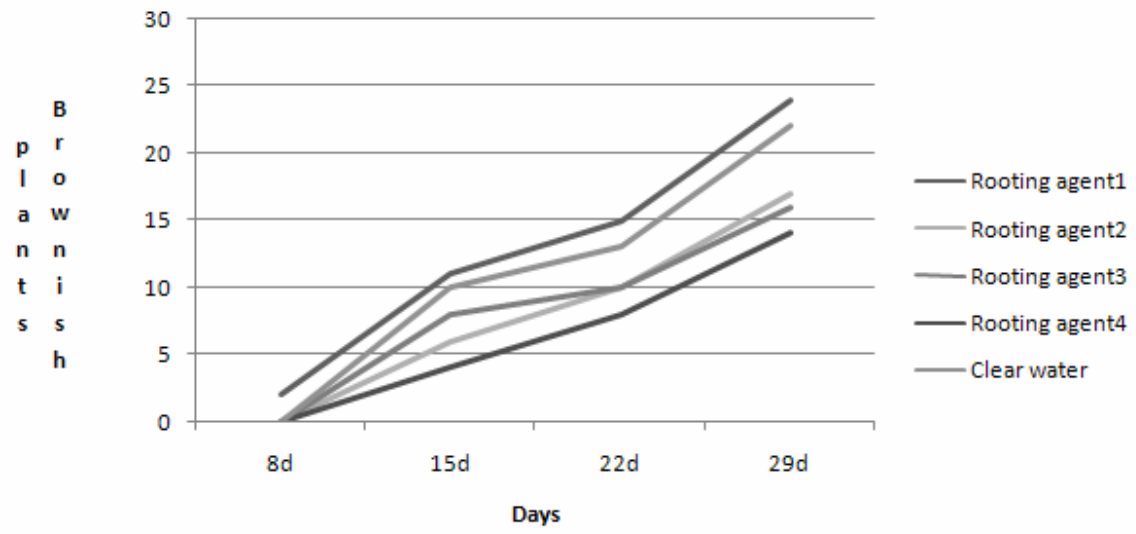

Fig. 4. Effects of four rooting agents on browning of the transplanted plants every after seven days to observe the number of brownish plantlets.

Four rooting agents were used to stimulate the formation of adventitious roots. The result showed that rooting agent No. 2 was more effective in promoting adventitious root formation than the other three agents. The effects of the rooting agent on number of adventitious roots showed a downward trend as follows: No. 2, No. 4, No. 3 and rooting No. 1 (Table 3). The main ingredient of rooting agent No. 2 is yellow humic acid increased photosynthetic rate of leaves due to decreased transpiration; promote rooting and rooting vigor.

In conclusion, the results presented in this paper provide evidence that too high a 2-ip concentration increased browning in the growth initiation phase for lowbush blueberry. Concentration of 2-ip $(15 \mathrm{mg} / \mathrm{l})$ is suitable for effective Blomidon propagation in vitro as well as for induction of adventitious shoot regeneration from excised stems of initial culture and subcultures. In vitro shoots 
can be rooted easily using $10 \mu \mathrm{M}$ IBA and ex vitro root growth in transplanted seedlings were found to be best in a humid chamber with rooting agent No. 2 treatment.

\section{References}

Cristoni A and Magistretti MJ (1987) Antiulcer and healing activities of Vaccinium mytrillus anthiocyanosides. Farmaco [Pratica] 42: 29-43.

Drucie J and Percival D (2003) Trends in lowbush blueberry cultivar development. Journal of the American Pomological Soc. 57: 63-69.

Eccher T, Noè N, Piagnani C and Castelli S (1986) Effects of increasing concentrations of BAP and 2iP on in vitro culture of Vaccinium corymbosum. Acta Hortic.179: 879-881.

Fukui H, Murakami Y, Harada T and Tamura T (1991) Response of highbush blueberry axillary leaf bud apices to growth regulators and its seasonal changes. Mem. Faculty Agric Hokkaido Univ.: 1-6 (in Japanese, with English abstract).

Gonzales MV, Lopez M, Valdes AE and Ordas RJ (2000) Micropropagation of three berry fruit species using nodal segments from field grown plants. Ann Appl. Biol. 137: 73-78.

Isutsa DK, Pritts MP and Mudge KW (1994) Rapid propagation of blueberry plants using ex vitro rooting and controlled acclimatization of micropropagules. Hort. Science. 29: 1124-1126.

Jaakola, Tolvanen and Laine Hohtola (2002) Micro-propagation of bilberry and lingonberry. Acta Hortic. 241: 401-403.

Julia M, Schwab M and Szankowski I (2007) Efficient in vitro regeneration systems for Vaccinium species. Plant Cell Tiss. Organ Cult. 676: 169-176.

Kalt W, Forney CF, Martin A and Prior RL (1999) Antioxidant capacity, vitamin C, phenolics, and anthocyanins after fresh storage of small fruits. J. Agr. Food Chem. 47: 4638-4644.

Kamei H, Kojima T, Hasegawa M, Koide T, Umeda T, Yukawa T and Terabe K (1995) Suppression of tumor cell growth by anthocyanins in vitro. Cancer Invest. 13:590-594.

Marcotrigiano M and McGlew S (1991) A two-stage micropropagation system for cranberries. J. Am. Soc. Hort. Sci. 116: 911-916.

Pereira MJ (2006) Conservation of Vaccinium cylindraceum Smith (Ericaceae) by Micropropagation Using Seedling Nodal Explants. In Vitro Cell 42: 65-68.

Samir C Debnath (2007) Influence of indole-3-butyric acid and propagation method on growth and development of in vitro and ex vitro derived lowbush blueberry plants. Plant Growth Regul. 676: 245-253.

Smagula JM and Harker J (1997) Cranberry micropropagation using a lowbush blueberry medium. Acta Hortic 447: 343-347.

Wang H, Muraleedharan G Nair and Gale M (1999) Antioxidant and anti-inflammatory activities of anthocyanins and their aglycon, cyanidin, from tart cherries. J. Nat. Prod 62: 294-296.

Yadong L, Rui H, Wei C, Jingyang F and Dechun Z (1994) Adaptability of blueberry to various acid soil type of Changbai Mountain area. Acta Horticulturae Sinica 21: $130-133$. 